\title{
Limited interspecific variation in grazing susceptibility of the brown alga Lobophora to herbivory
}

\author{
Vieira Christophe ${ }^{1,{ }^{*}}$, Stenger Pierre-Louis ${ }^{2}$, Moleana Thibaud ${ }^{3,4}$, De Clerck Olivier ${ }^{1}$, Payri Claude ${ }^{5}$
}

\begin{abstract}
${ }^{1}$ Phycology Research Group, Center for Molecular Phylogenetics and Evolution, Ghent University, Krijgslaan 281 (S8), B-9000 Gent, Belgium

2 IFREMER, UMR 241 Ecosystèmes Insulaires Océaniens, Labex Corail, Centre Ifremer du Pacifique, BP 49, 98725 Tahiti, French Polynesia

3 Université de la Nouvelle-Calédonie, Laboratoire LIVE et LABEX « Corail », BP R4, 98851 Nouméa, New Caledonia

${ }^{4}$ Aqualagon SARL, BP 2525 Mont-Dore, 98800 Nouméa, New Caledonia

5 UMR ENTROPIE (IRD, UR, CNRS), LabEx-CORAIL, Institut de Recherche pour le Développement,

B.P. A5, 98848 Nouméa Cedex, Nouvelle-Calédonie, France
\end{abstract}

*Corresponding author : Christophe Vieira, email address : christophe.vieira@ugent.be

\begin{abstract}
:
The genus Lobophora is a notable benthic algal component of tropical coral reefs, capable of dominating large reef areas following coral mortality and herbivory declines. The alga, however, has been the object of contradictory observations in terms of susceptibility to herbivory. Unaware of the species-richness of this genus, most studies referred to Lobophora variegata, a species assumed to present various morphotypes and chemotypes, occupying diverse ecological niches. Variation in susceptibility to herbivory has been consequently interpreted as intraspecific variation in terms of morphology and chemical composition as well as differences in herbivore guild compositions and diet across different locations (e.g., habitat, reef, region). Recent taxonomic studies of Lobophora disclosed a high species diversity, which could explain previous conflicting observations. The present study tested the grazing susceptibility of seven species of Lobophora (L. dimorpha, L. hederacea, L. monticola, L. obscura, $L$. rosacea, $L$. sonderi and $L$. undulata), which differ in growth form as well as in their chemical composition and fine-scale ecological niche on coral reefs in the southern lagoon in New Caledonia, to two important herbivores in New Caledonia, the rabbitfish Siganus lineatus and the sea urchin Diadema setosum using tank, cage, and in situ experiments. All seven Lobophora species were markedly consumed in situ and by the two herbivores. Differences in consumption among the Lobophora species were small but statistically significant. Lobophora rosacea, characterized by a distinct secondary metabolome, was significantly more consumed by the two herbivores. Conversely, L. sonderi was always among the least consumed species. These results point to the possible role of chemical defense, and suggest that $L$. rosacea may produce less or different chemical deterrents than the other Lobophora species, and that $L$. sonderi may produce deterrents active over a wider range of herbivores. However, the limited interspecific differences in consumption point to the greater importance of associational and spatial refuges as defense strategies against herbivores over chemical or morphological defenses in the genus Lobophora.
\end{abstract}




\section{Highlights}

- This is the first experimental study to specifically test interspecific grazing susceptibility in the brown alga Lobophora. Grazing susceptibility of seven Lobophora species was tested in situ and in controlled systems to two herbivores. All Lobophora species were markedly consumed by the herbivorous fish Siganus lineatus and the sea urchin Diadema setosum. Limited interspecific differences in consumption were observed between the seven Lobophora species in all experiments. Results indicate limited effects of morphology and chemical composition among species in their grazing susceptibility.

Keywords : Defense, Escape, Herbivory, Lobophora, Macroalgae 


\section{Introduction}

The brown algal genus Lobophora J.Agardh (1894) (Dictyotales, Phaeophyceae) is a common seaweed of tropical coral reefs. Following natural and anthropogenic disturbances, it has recurrently bloomed in reefs that have shifted from coral- to macroalgal-dominated assemblages (e.g. De Ruyter van Steveninck \& Breeman 1987b, Diaz-Pulido et al. 2009). These large-scale events illustrate how in normal conditions Lobophora cover is regulated by processes including herbivory and competition for space notably with corals. For instance, the mass mortality of Diadema antillarum in the Caribbean in the mid-80s (De Ruyter van Steveninck \& Breeman 1987b, Steneck 1993) but also herbivore exclusion experiments (Kennelly 1991, Jompa \& McCook 2002a, b, Diaz-Pulido \& McCook 2003, Burkepile \& Hay 2008, Morrow et al. 2011) resulted in a significant increase in Lobophora indicating the intense consumption necessary to restrict the algal cover.

Grazing experiments resulted in contrasting observations in terms of consumption, with studies showing low (Pillans et al. 2004) to high (Lewis 1985) preference for Lobophora relative to other macroalgae, but also large differences in Lobophora consumption by members of the same family (Pillans et al. 2004, Bennett et al. 2010), or even from the same species (De Ruyter van Steveninck \& Breeman 1987a, b, Morrison 1988, Solandt \& Campbell 2001, Tuya et al. 2001). Contrasting observations in terms of Lobophora consumption have been ascribed to chemical and morphological differences among different morphotypes/ecotypes of the species $L$. variegata. Some authors attributed the low preference for Lobophora by herbivores (e.g., sea urchin, fishes and sea snails; Bolser \& Hay 1996, Pillans et al. 2004, Ng et al. 2013) to the presence of feeding deterrents such as polyphenolic secondary metabolites (e.g., phlorotannins; Targett et al. 1995, Bolser \& Hay 1996, Arnold \& 
Targett 1998, 2000). In this sense, Bolser and Hay (1996) attributed the greater consumption of Lobophora by Diadema antilliarum in temperate (North Carolina) versus tropical (Bahamas) regions to the higher concentrations of phlorotannins. In addition, Lobophora resistance to herbivory was associated to its morphology, i.e., structural defense (Littler 1980, Steneck \& Watling 1982). Coen and Tanner (1989) showed differential susceptibilities to herbivory by fish and crabs among different morphotypes. Conversely, Vergés et al. (2011) did not find differences in consumption between reef flat-decumbent and lagoon-ruffled morphotypes.

Previous work on Lobophora susceptibility to herbivory has used individuals from the same species (i.e., L. variegata) with intraspecific variations (i.e., contrasting morphotypes, chemotypes and growing at different depths or locations (Coen \& Tanner 1989, Vergés et al. 2011)). However, in the light of recent molecular studies, which revealed high species diversity in Lobophora, with over 100 species worldwide (Vieira et al. 2016, Vieira et al. 2017, Vieira et al. 2018, Camacho et al. 2019, Vieira et al. 2019), these previous studies were most likely studying different species of Lobophora, and thus were comparing grazing susceptibility among different species and not among different morphotypes or chemotypes of a single species.

With our best knowledge of Lobophora species diversity, the present study aims to test interspecific variation in susceptibility to herbivory. A review on the species diversity in New Caledonia indicated that the genus contains at least 31 species in this archipelago located East of Australia, and that Lobophora species have developed very specific ecological niches together with morphologies. Seven species commonly found in the Southwestern lagoon of New Caledonia and presenting characteristic morphologies and ecologies (Vieira et al. 2014) were selected for this study (L. dimorpha C.W.Vieira, Payri \& De Clerck, L. hederacea C.W.Vieira, 
Payri \& De Clerck, L. monticola C.W.Vieira, Payri \& De Clerck, L. obscura (Dickie) C.W.Vieira, De Clerck \& Payri, L. rosacea C.W.Vieira, Payri \& De Clerck, L. sonderi C.W.Vieira, De Clerck \& Payri and L. undulata C.W.Vieira, Payri \& De Clerck; Figs 1, S1). Morphologies range from tightly crustose (e.g., L. obscura) to stipitate (e.g., L. sonderi) forms with intermediate growth forms including procumbent (e.g., L. dimorpha), decumbent (e.g., L. hederacea, L. undulata, L. monticola) and ruffled (e.g., L. rosacea). The rigidity of their thallus is linked to their thickness also varying among species (Table 1). These species grow on different substrates and reef types, characterized by specific depth, hydrodynamism, herbivory intensity and benthos composition (Vieira et al. 2014). For instance, L. obscura commonly grows on coral rubbles and rocks at shallow depths where herbivory is rather low because of high wave exposure. In contrast $L$. rosacea and $L$. hederacea grow in coral dominated habitat down to 5 meters where herbivory is more intense, niched amongst branching corals. Lobophora hederacea is commonly found in the inner barrier reef, while L. rosacea is more common on fringing and islet reefs within the lagoon. In contrast, L. sonderi grows in low herbivory and less exposed habitats (e.g., leeward side of islets) such as in macroalgal beds typically dominated by Sargassum and Turbinaria or on sand bottoms below 5 meters depth. Some species also present different ecotypes such as L. rosacea either found nested amongst coral branches or epiphytic on $L$. sonderi (Fig. S1f). Metabolomics fingerprints of six New Caledonian species of Lobophora (L. dimorpha, L. hederacea, L. obscura, L. rosacea, L. sonderi and L. undulata,) provide evidence for clear chemical compositional differences among species (Vieira et al. 2016b). These metabolomics analyses showed that these six 
species displayed characteristic secondary metabolomics profiles, with one species, $L$. rosacea, particularly standing out (Fig. S2).

The present study aims to test the grazing susceptibility of seven Lobophora species from New Caledonia to two important herbivores in New Caledonia, the rabbitfish Siganus lineatus and the sea urchin Diadema setosum using tank, cage, aquarium and in situ experiments. The study has for dual objectives to test the consumption of Lobophora by different herbivores and to compare the relative preference for species that are morphologically and chemically different.

\section{Material and methods}

Three grazing experiments were performed in the southwest lagoon of New Caledonia in April 2014, in the fish farm Aqualagon (Baie N'go, New Caledonia), in the natural environment, and aquariums of the Institut de Recherche pour le Développement (IRD) in Noumea. In all experiments, Lobophora thalli from different species were alternatively and equidistantly disposed along lines in a semi-random manner, i.e., while we made sure that individuals from the same species were never next to each other, the placement of species was random to avoid any bias. All experiments lasted $24 \mathrm{~h}$.

\subsection{Lobophora sampling}

Seven Lobophora species (L. dimorpha, L. hederacea, L. monticola, L. obscura, L. rosacea, L. sonderi and L. undulata,) were collected on SCUBA in different localities (Table S1) within the southwestern lagoon of New Caledonia on the $16^{\text {th }}$ of April 2014. Lobophora samples were collected, kept in a cooler, for less than $2 \mathrm{~h}$, until treatment in the lab. 


\subsection{Fish farm experiments}

The grazing experiments in the fish farm were conducted in fish tanks $\left(3 \mathrm{~m}^{3}\right.$; Fig. S3a) and in circular open-water fish cages ( $8 \mathrm{~m}$ in diameter $\times 6 \mathrm{~m}$ in depth) with a single species of rabbitfish (Fig. S3b), Siganus lineatus (Valenciennes, 1835), a common fish in New Caledonia and identified as a prominent herbivore in the Great Barrier Reef (Mantyka \& Bellwood 2007). Lobophora species were inserted in threestranded polypropylene lines. For the tank experiments, the lines were $1 \mathrm{~m}$ long and the samples were fixed $10 \mathrm{~cm}$ from each other. For the cage experiments, the lines were $5 \mathrm{~m}$ long and specimens were fixed every $15 \mathrm{~cm}$. The lines were disposed vertically in the tubs and net pens. Grazing susceptibility of Lobophora was tested on juveniles and commercial size of $S$. lineatus, in the tanks ( 2 adult tanks, 1 juvenile tank) and the cage ( 2 juvenile cages, 1 adult cage). The density of fishes in the adult tanks was of 3-5 fish.m ${ }^{-3}$ and in the juvenile tank of around 25 fish.m ${ }^{-3}$.

\subsection{In situ experiments}

In situ experiments took place in different reefs in front of Noumea. Triplicates of 20 $\mathrm{m}$ lines were deployed at five different sites (Table S2). Lobophora thalli were inserted every $25 \mathrm{~cm}$ between strands of three-stranded polypropylene lines (Fig. S3c). We used ten replicates per species, resulting in 80 algal thalli per line. Lines were fixed horizontally by metal rods, at $1 \mathrm{~m}$ above the lagoon floor.

\subsection{Aquarium experiments}

Grazing experiments in the aquarium were conducted with the sea urchin Diadema setosum (Lesk, 1778), a common grazer in the Pacific tropical region. The seven Lobophora species were alternatively stapled along a nylon fishing line, and fixed on the aquarium bottom using diving weights (Figs S3d, S4). Nine lines (which represent nine replicates per species) were distributed in three aquariums, which represent a 
total of 21 Lobophora specimens (i.e., 7 species $\times 3$ replicates) per aquarium (Fig. S4). In each aquarium four individuals of sea urchins were put together (Fig. S4).

\subsection{Algal consumption rates}

To measure the algal biomass consumed, we measured the algal dry-blotted weight before and after the grazing experiments to the nearest $0.001 \mathrm{~g}$. Given the significant differences of thallus size and thicknesses, we also calculated the percentage of alga consumed. ANOVA's were performed on both the total consumed biomass and the percentage consumed. Results for each experiment (in situ, fish farm and aquarium) were pooled and averaged.

\subsection{Statistical analyses}

Normality of results was tested with the Shapiro-Wilk test. If the responses violated parametric assumptions, grazing results were evaluated using the Kruskal-Wallis $\mathrm{H}$ tests followed by Tukey honest significant difference (HSD) post hoc comparisons test for significant Kruskall-Wallis findings. If data respected the parametric assumptions, a one-way ANOVA was performed followed by the Tukey post hoc HSD test for significant ANOVA findings. Statistical analyses were performed using the computing environment R (R Development Core Team 2013).

\section{Results}

\subsection{Fish farm grazing experiment}

All Lobophora species were consumed by $S$. lineatus, with an average consumption of algal material ranging from $48 \pm 23$ ( \pm s.d.; L. dimorpha) to $158 \pm 54 \mathrm{mg}(L$. monticola); and percentage of alga consumed ranging between $38 \pm 26$ (L. undulata) and $53 \pm 30 \%$ (L. rosacea) (Fig. 2a). Considering the percentage of the alga 
consumed, no significant differences were observed among six Lobophora species $(L$. obscura, L. monticola, L. sonderi, L. hederacea, L. dimorpha, L. undulata) with an average of alga consumed of $39 \pm 26 \%$ (ranging from 37 to $41 \%$ ) (Fig. 2a). With an average of $53 \pm 30 \%$, L. rosacea consumption was significantly higher than the other Lobophora species (one-way ANOVAs, $p=9.92 . e-14$ (percentage consumed)).

\subsection{In situ grazing experiment}

All Lobophora species were consumed during the in situ experiments, with an average consumption of algal material for each species ranging between $34 \pm 20(L$. dimorpha) and $116 \pm 42 \mathrm{mg}$ (L. monticola); and in percentage of alga consumed ranging between $47 \pm 23$ (L. sonderi) to $69 \pm 20 \%$ (L. monticola) (Fig. 2b). Significant differences in consumption were observed for in situ grazing experiments among the seven species of Lobophora (Fig. 2b) (one-way ANOVAs, $p<2 \mathrm{e}-16$ (biomass consumed) and $p=5.27 \mathrm{e}-14$ (percentage consumed)). Lobophora monticola, L. hederacea and L. obscura were significantly more consumed than the other species, when considering the percentage of biomass consumed.

\subsection{Aquarium grazing experiment}

All Lobophora species were consumed by the sea urchin D. setosum, with an average consumption of algal material for each species ranging between $31 \pm 3$ (L. dimorpha) and $120 \pm 12 \mathrm{mg}$ (L. rosacea); and in percentage of alga consumed ranging between $66 \pm 7$ (L. monticola) and $83 \pm 8 \%$ (L. rosacea) (Fig. 2c). Significant differences in consumption (Fig. 2c) were observed among the seven species of Lobophora (oneway ANOVAs, $p=0.00704$ (biomass consumed) and $p<2 \mathrm{e}-16$ (percentage consumed)). No significant differences were observed among $L$. obscura, $L$. monticola and L. sonderi, nor between L. hederacea and L. dimorpha. Lobophora 
undulata followed by L. rosacea were significantly more consumed than the rest of the Lobophora species.

\section{Discussion}

\subsection{Interspecific differences in grazing susceptibility}

The present study assessed the susceptibility to herbivory of seven different species of Lobophora presenting contrasting morphologies, chemical compositions and ecologies. We experimentally forced the contact between algae and herbivores, which naturally would not necessarily be the case. All Lobophora species were markedly consumed with small but significant interspecific differences, in situ and by two important herbivores in New Caledonia, the rabbitfish S. lineatus and the sea urchin D. setosum. Differences in the significantly most consumed species in the three experiments ( $L$. rosacea by $S$. lineatus; L. monticola, L. hederacea and L. obscura in situ; L. undulata and $L$. rosacea by $D$. setosum) may indicate slight differences in food preferences among herbivores. Lobophora rosacea was nonetheless significantly more consumed by the two herbivores, and L. sonderi was among the least consumed in all experiments.

\subsection{Chemical defenses?}

The chemical composition analyses from Vieira et al. (2016) revealed two main trends: (1) each species is characterized by a distinct chemical composition, and (2) major differences are found in the chemical composition of L. rosacea compared to the other Lobophora species. While the differences are small, both the fish farm and aquarium experiments revealed statistically significant differences in consumption 
rates among species. Moreover, in both cases, L. rosacea was the first or second most eaten species within the Lobophora genus. These results may point to a correlation between chemical composition and herbivore consumption, suggesting that L. rosacea produces less or different chemical deterrents than the other species, and that these are less effective against the two tested herbivores. Conversely, the fact that Lobophora sonderi was in all experiments among the least consumed species could indicate that this species is chemically better defended against a wider range of herbivores than the other Lobophora species.

\subsection{Refuge over defense?}

The limited interspecific differences in grazing susceptibility suggests that morphological or chemical differences among Lobophora species do not remarkably affect $S$. lineatus and $D$. setosum food choice. This leads us to dispute that while chemicals and morphological defenses have been suggested previously as major strategies against herbivores, they may eventually play a limited role as a strategy against herbivory in Lobophora species. Alternatively, and largely overlooked until now, refuge would appear to be an important strategy against herbivores. We argue that species from the genus Lobophora adopt two major refuge strategies, namely (1) spatial and (2) associational refuge as chief stratagems against herbivory. A review of the diversity of the genus in New Caledonia, showed that Lobophora species had distinct habitat and substratum preferences (e.g., bedrocks, coral rubbles, live and dead corals; Vieira et al. 2014).

\subsection{Spatial and associational refuges}

Spatial refuge has been evidenced by De Ruyter van Steveninck and Breeman (1987a) who showed that Lobophora abundance was negatively correlated with Diademum 
antiallarum density. In Curaçao, the erect golden-brown Lobophora species has refuge from herbivores in deep waters. In New Caledonia, L. obscura is mainly found in shallow wave-washed habitats consisting of bedrock, rocks, coral rubbles. The latter has thick blades and adheres strongly to the substratum, which is characteristic of intertidal populations and considered to be adaptations to increased water motion and desiccation (Norton et al. 1981). In this habitat, herbivore presence is limited due to high hydrodynamism. Consequently, L. obscura finds spatial refuge from herbivores in this habitat.

Lobophora hederacea, L. monticola, L. undulata and L. rosacea are commonly found associated to branching corals and notably the genera Acropora, Montipora, Porites, Stylophora, Pocillopora and Seriatopora (Diaz-Pulido et al. 2009, Bennett et al. 2010, Vieira et al. 2014, Vieira et al. 2015). Lobophora rosacea adopts a ruffled form and grows mainly amongst Acropora coral branches. The other Lobophora species are usually decumbent, attached by their basal part to coral branches, or form crusts predominantly at the basal part of the coral branches, where access by large herbivores is difficult. In the Great Barrier Reef, populations of Lobophora growing amongst branching Acropora were less consumed than populations located in planar habitats, suggesting that branching corals act as a refuge for Lobophora from herbivores (Bennett et al. 2010). Jompa and McCook (2002a) also concluded that the coral Porites cylindrica structure provides a refuge for Lobophora from herbivory. The refuge role played by branching corals is furthermore supported by the rare presence of Lobophora with other coral forms in the same habitat (author's personal observations).

It was suggested that palatable prey may typically be protected from consumers by living in association with less preferred prey (e.g., Poore \& Hill 2005). Lobophora 
sonderi usually grows in sand-covered habitats, characterized by low grazing intensity, amidst other algae such as Turbinaria and Sargassum, both tough spiky and upright brown algae, which are less edible because of morphological and chemical defenses (Bittick et al. 2010). Turbinaria ornata has been previously reported to represent a herbivory refuge for associated algae (Hay 1986, Bittick et al. 2010). This refuge is not only associational but also spatial, as algal beds outside coral reefs experience low grazing intensity. Lobophora rosacea, which presents two distinct ecotypes, either finds refuge with branching Acropora or in algal beds as an epiphyte to $L$. sonderi.

\section{Conclusion}

The present contribution represents the first experimental study to specifically test interspecific grazing susceptibility in the brown alga Lobophora. This study primarily showed that all Lobophora species were markedly consumed by S. lineatus and D. setosum, and that interspecific differences were limited. Although trivial, the trends of two species, L. rosacea and L. sonderi, may point to the role of chemical defense. Significantly more consumed by the two herbivores and characterized by a distinct secondary metabolome, L. rosacea may produce less or different chemical deterrents than the other Lobophora species. On the contrary, significantly less consumed in all experiments, L. sonderi may produce chemicals deterrents active against a wide range of herbivores. While it was previously suggested that Lobophora resists herbivory by relying essentially on chemical deterrents and structural defense, present results suggest that differences in morphology and secondary metabolome may play a rather limited role in defense against herbivores. Instead, Lobophora may primarily find refuge from herbivory by growing in specific habitats or associated to 
certain organisms. Future studies need to identify exactly which herbivores feed on Lobophora spp. in the natural environment, and determine if these herbivores vary among species of Lobophora. 


\section{Acknowledgements}

We are grateful to Aqualagon's owner, Frank Le Garrec, for letting us perform the grazing experiments in their fish farm, and to its crew, Renaud Condoya and MarieClaude Qalue, for assisting us in the deployment of the experiments at the fish farm. We also thank Julie Gaubert and the IRD boat crew, Miguel Clarque, Samuel Tereua and Philippe Naudin, for assisting us in the deployment of the experiments in situ. C. Vieira is a PhD fellow of the University of Pierre and Marie Curie and Ghent University and is part of MARES, a Joint Doctorate programme selected under Erasmus Mundus coordinated by Ghent University (FPA 2011-0016). 


\section{References}

Arnold TM, Targett NM (1998) Quantifying in situ rates of phlorotannin synthesis and polymerization in marine brown algae. J Chem Ecol 24:577595

Arnold TM, Targett NM (2000) Evidence for metabolic turnover of polyphenolics in tropical brown algae. J Chem Ecol 26:1393-1410

Bennett S, Vergés A, Bellwood D (2010) Branching coral as a macroalgal refuge in a marginal coral reef system. Coral Reefs 29:471-480

Bittick SJ, Bilotti ND, Peterson HA, Stewart HL (2010) Turbinaria ornata as an herbivory refuge for associate algae. Mar Biol 157:317-323

Bolser RC, Hay ME (1996) Are tropical plants better defended? Palatability and defenses of temperate vs. tropical seaweeds. Ecology 77:2269-2286

Burkepile DE, Hay ME (2008) Herbivore species richness and feeding complementarity affect community structure and function on a coral reef. Proc Natl Acad Sci USA 105:16201-16206

Camacho 0, Fernández-García C, Vieira C, Gurgel CFD, Norris J, Freshwater DW, Fredericq S (2019) The genus Lobophora (Dictyotales, Phaeophyceae) in the Western Atlantic and Eastern Pacific Oceans with the Description of Eight New Species. J Phycol

Coen L, Tanner C (1989) Morphological variation and differential susceptibility to herbivory in the tropical brown alga Lobophora variegata. Marine Ecology Press Series 54:287-298

De Ruyter van Steveninck E, Breeman A (1987a) Deep water populations of Lobophora variegata (Phaeophyceae) on the coral reef of Curaçao: influence of grazing and dispersal on distribution patterns. Mar Ecol Prog Ser 38:241-250

De Ruyter van Steveninck E, Breeman A (1987b) Deep water vegetations of Lobophora variegata (Phaeophyceae) in the coral reef of Curacaopopulation dynamics in relation to mass mortality of the sea urchin Diadema antillarum. Mar Ecol Prog Ser 36:81-90

Diaz-Pulido G, McCook LJ (2003) Relative roles of herbivory and nutrients in the recruitment of coral-reef seaweeds. Ecology 84:2026-2033

Diaz-Pulido G, McCook LJ, Dove S, Berkelmans R, Roff G, Kline DI, Weeks S, Evans RD, Williamson DH, Hoegh-Guldberg $O$ (2009) Doom and boom on a resilient reef: climate change, algal overgrowth and coral recovery. PLoS One 4:e5239

Hay ME (1986) Associational plant defenses and the maintenance of species diversity: turning competitors into accomplices. Am Nat:617-641

Jompa J, McCook LJ (2002a) Effects of competition and herbivory on interactions between a hard coral and a brown alga. J Exp Mar Biol Ecol 271:25-39

Jompa J, McCook LJ (2002b) The effects of nutrients and herbivory on competition between a hard coral (Porites cylindrica) and a brown alga (Lobophora variegata). Limnol Oceanogr 47:527-534

Kennelly SJ (1991) Caging experiments to examine the effects of fishes on understorey species in a sublittoral kelp community. J Exp Mar Biol Ecol 147:207-230 
Lewis SM (1985) Herbivory on coral reefs: algal susceptibility to herbivorous fishes. Oecologia 65:370-375

Littler MM (1980) Morphological form and photosynthetic performances of marine macroalgae: tests of a functional/form hypothesis. Bot Mar 23:161-166

Mantyka C, Bellwood D (2007) Direct evaluation of macroalgal removal by herbivorous coral reef fishes. Coral Reefs 26:435-442

Morrison D (1988) Comparing fish and urchin grazing in shallow and deeper coral reef algal communities. Ecology:1367-1382

Morrow K, Paul V, Liles M, Chadwick N (2011) Allelochemicals produced by Caribbean macroalgae and cyanobacteria have species-specific effects on reef coral microorganisms. Coral Reefs 30:309-320

Ng CSL, Toh TC, Toh KB, Guest J, Chou LM (2013) Dietary habits of grazers influence their suitability as biological controls of fouling macroalgae in $e x$ situ mariculture. Aquacult Res

Norton T, Mathieson A, Neushul M (1981) Morphology and environment. The biology of seaweeds 421:451

Pillans R, Franklin C, Tibbetts I (2004) Food choice in Siganus fuscescens: influence of macrophyte nutrient content and availability. J Fish Biol 64:297-309

Poore AG, Hill NA (2005) Spatial associations among palatable and unpalatable macroalgae: a test of associational resistance with a herbivorous amphipod. J Exp Mar Biol Ecol 326:207-216

R Development Core Team (2013) R: a language and environment for statistical computing. The R Foundation for Statistical Computing, Institute for Statistics and Mathematics, Vienna, Austria. http://cran.r-project.org.

Solandt J-L, Campbell AC (2001) Macroalgal feeding characteristics of the sea urchin Diadema antillarum Philippi at Discovery Bay, Jamaica. Caribb J Sci 37:227-238

Steneck R, Watling L (1982) Feeding capabilities and limitation of herbivorous molluscs: a functional group approach. Mar Biol 68:299-319

Steneck RS Is herbivore loss more damaging to reefs than hurricanes? Case studies from two Caribbean reef systems (1978-1988). Proc Proceedings of the Colloquium on Global Aspects of Coral Reefs: Health, Hazards and History

Targett NM, Boettcher AA, Targett TE, Vrolijk NH (1995) Tropical marine herbivore assimilation of phenolic-rich plants. Oecologia 103:170-179

Tuya F, Martín J, Reuss G, Luque A (2001) Food preferences of the sea urchin Diadema antillarum in Gran Canaria (Canary Islands, central-east Atlantic Ocean). Journal of the Marine Biological Association of the UK 81:845-849

Vergés A, Vanderklift MA, Doropoulos C, Hyndes GA (2011) Spatial patterns in herbivory on a coral reef are influenced by structural complexity but not by algal traits. PLoS One 6:e17115

Vieira C, Aharonov A, Paz G, Tsiamis K, Engelen A, Einav R, De Clerck O (2018) Diversity and origin of the genus Lobophora (Dictyotales, Phaeophyceae) from the Mediterranean Sea including the description of two new species. Phycologia 
Vieira C, Camacho O, Sun Z, Fredericq S, Leliaert F, Payri C, De Clerck O (2017) Historical biogeography of the highly diverse brown seaweed Lobophora (Dictyotales, Phaeophyceae). Mol Phylogen Evol 110:81-92

Vieira C, Camacho O, Wynne MJ, Mattio L, Anderson R, Bolton JJ, Sansón M, D'Hondt S, Leliaert F, Fredericq S, Payri C, De Clerck $O$ (2016) Shedding new light on old algae: matching names and sequences in the brown algal genus Lobophora (Dictyotales, Phaeophyceae). Taxon 65:689-707

Vieira C, D'hondt S, De Clerck O, Payri CE (2014) Toward an inordinate fondness for stars, beetles and Lobophora? Species diversity of the genus Lobophora (Dictyotales, Phaeophyceae) in New Caledonia. J Phycol 50:1101-1119

Vieira C, De Clerck O, Millet L, Payri CE (2019) Description of 10 new Lobophora species from the Bismarck Sea (Papua New Guinea). Phycol Res

Vieira C, Payri C, De Clerck $O$ (2015) Overgrowth and killing of corals by the brown alga Lobophora hederacea (Dictyotales, Phaeophyceae) on healthy reefs in New Caledonia: a new case of the epizoism syndrome. Phycol Res 63:152-153 


\section{Figures captions}

Figure 1. External morphology of the six Lobophora species (L. obscura (a), L. undulata (b), L. hederacea (c), L. rosacea (d), L. dimorpha (e), L. sonderi (f), L. monticola $(\mathrm{g}))$ used in the grazing experiments.

Figure 2. Grazing experiments results with seven Lobophora species in three grazing experiments: natural environment (a), fish farm (b), and sea-urchin aquarium experiments (c). Barplots represent the average percentage of alga consumed. Letters indicate distinct groupings based on post-hoc statistical comparison among Lobophora species. Error bars represent standard deviation of the mean.

Figure S1. Habit photographs of the six Lobophora species (L. obscura (a), L. undulata (b), L. hederacea (c), L. rosacea (d), L. sonderi (e), L. rosacea (left arrow) epiphytic on L. sonderi (right arrow) (f), L. monticola (g)) used in the grazing experiments.

Figure S2. Principal Component Analysis (PCA) of metabolomic profiles of six Lobophora species used in the grazing experiments. Lobophora monticola is missing from this analysis. ${ }^{*} L$. rosacea niched amongst corals. ${ }^{*} L$. rosacea epiphytic on $L$. sonderi.

Figure S3. Pictures of fish farm experiment (a), rabbitfish (b), natural environment experiment (c) and aquarium experiment (d).

Figure S4. Diagram of experimental setup for the sea-urchin aquarium grazing experiment. Three nylon fishing lines were disposed to the bottom of the aquarium fixed on each extremity by diving weights. Lobophora thalli from different species were randomly stapled at equidistance along the lines. 


\section{Tables}

Table 1. Description of the Lobophora species tested in the grazing experiments

\begin{tabular}{|c|c|c|c|c|}
\hline & Morphology & $\begin{array}{l}\text { Thickness } \\
(\mu \mathrm{m})\end{array}$ & Habitat & Substrate \\
\hline L. dimorpha & $\begin{array}{l}\text { Procumbent, } \\
\text { Stipitate }\end{array}$ & $101.2 \pm 12.8$ & Coral dominated & Coral basal part, bedrock \\
\hline L. hederacea & $\begin{array}{l}\text { Shelf-like (decumbent), } \\
\text { Crustose }\end{array}$ & $188.6 \pm 26.1$ & Coral dominated & Coral basal part, live coral branches \\
\hline L. monticola & Shelf-like (decumbent) & $152.9 \pm 24.4$ & Coral dominated & Dead coral basal part, live coral branches \\
\hline L. obscura & Crustose & $291.6 \pm 39.8$ & $\begin{array}{l}\text { Shallow exposed reefs } \\
\text { coral rubbles }\end{array}$ & Dead coral, coral rubble, bedrock, rock \\
\hline L. rosacea & $\begin{array}{l}\text { Fasciculate (ruffled), } \\
\text { Decumbent }\end{array}$ & $146.5 \pm 16$ & $\begin{array}{l}\text { Coral dominated, } \\
\text { macroalgal beds }\end{array}$ & Coral basal part \\
\hline L. sonderi & Stipitate & $211.2 \pm 8.2$ & $\begin{array}{l}\text { Macroalgal beds, } \\
\text { sand bottoms }\end{array}$ & Bedrock, loose rock, sand \\
\hline L. undulata & Shelf-like (decumbent) & $214 \pm 52.3$ & Coral dominated & Coral basal part \\
\hline
\end{tabular}

Table S1. Sites were the Lobophora species were collected in the southwestern lagoon of New Caledonia

\begin{tabular}{llll}
\hline Species & Locality & Latitude & Longitude \\
\hline Lobophora dimorpha & Senez & -22.220141 & 166.33441 \\
Lobophora hederacea & Grand recif Abore & -20.7161 & 165.141 \\
Lobophora monticola & Baie Sainte Marie & -22.297713 & 166.481639 \\
Lobophora obscura & Ricaudy & -22.315317 & 166.457717 \\
Lobophora rosacea & Ricaudy & -22.315317 & 166.457717 \\
Lobophora sonderi & Crouy & -22.3517 & 166.3514 \\
Lobophora undulata & Ilot Laregnere & -22.288783 & 166.427983 \\
\hline
\end{tabular}

Table S2. In situ sites location

\begin{tabular}{lllccc}
\hline Reef name & Reef type & Habitat & Depth (m) & Latitude & Longitude \\
\hline Crouy & Patch reef & Algae bed & 2 & $22^{\circ} 21.114$ & $166^{\circ} 21.084$ \\
Larégnère & Islet reef & Sandy bottom & 2 & $22^{\circ} 19.524$ & $166^{\circ} 18.953$ \\
Canard 1 & Islet reef & Coral reef & 2 & $22^{\circ} 18.840$ & $166^{\circ} 26.266$ \\
Canard 2 & Islet reef & Coral reef & 4 & $22^{\circ} 18.855$ & $166^{\circ} 26.289$ \\
Canard 3 & Islet reef & Coral reef & 7 & $22^{\circ} 18.858$ & $166^{\circ} 26.317$ \\
Senez & Patch reef & Coral reef & 2 & $22^{\circ} 17.760$ & $166^{\circ} 19.975$ \\
Abore & Back reef & Coral reef & 1 & $22^{\circ} 27.001$ & $166^{\circ} 22.271$ \\
\hline
\end{tabular}


(a)

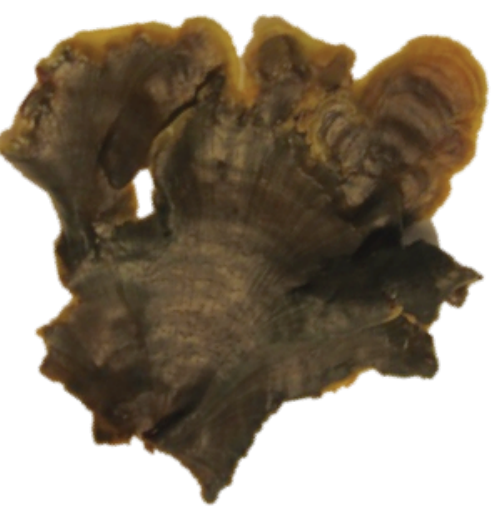

(d)

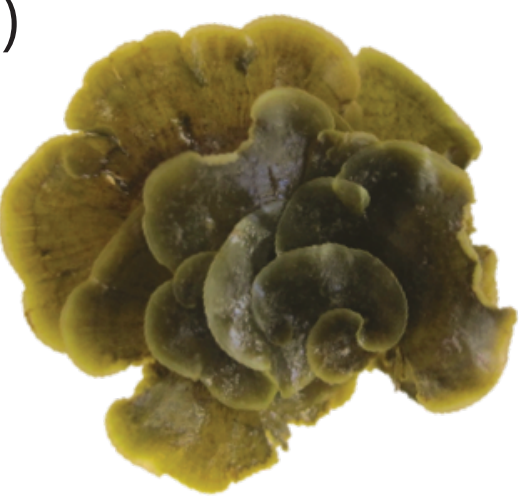

(b)

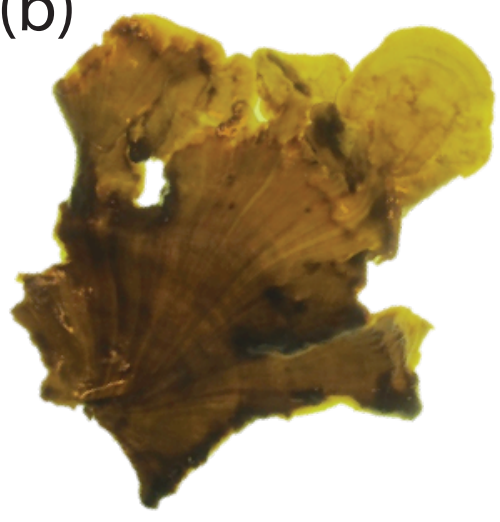

(e)

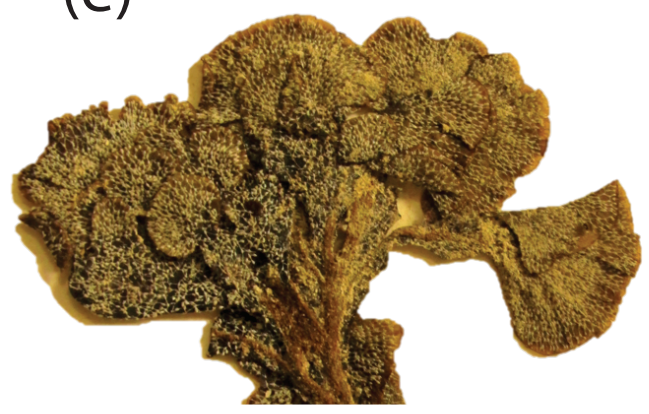

(g)

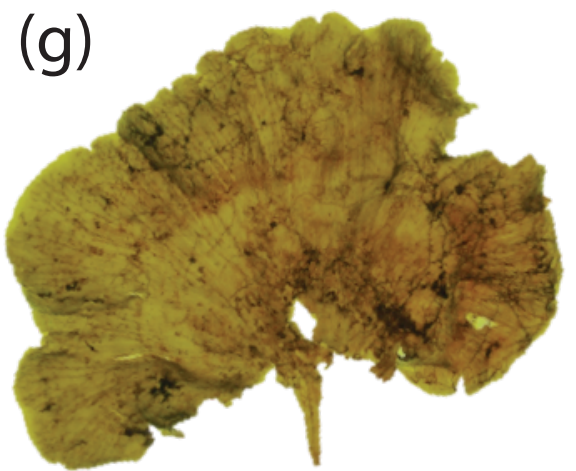

(c)

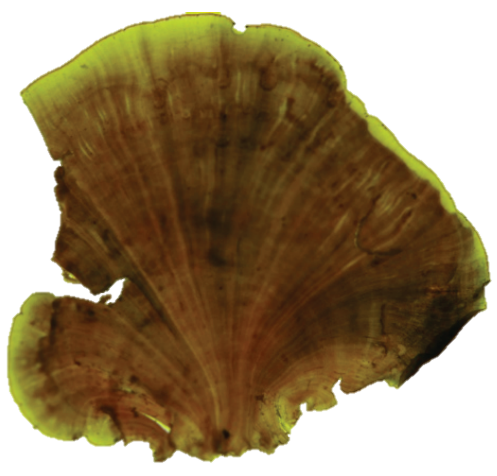

(f)

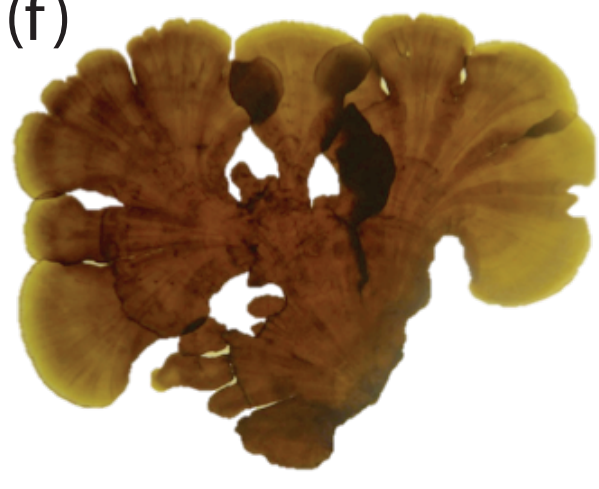




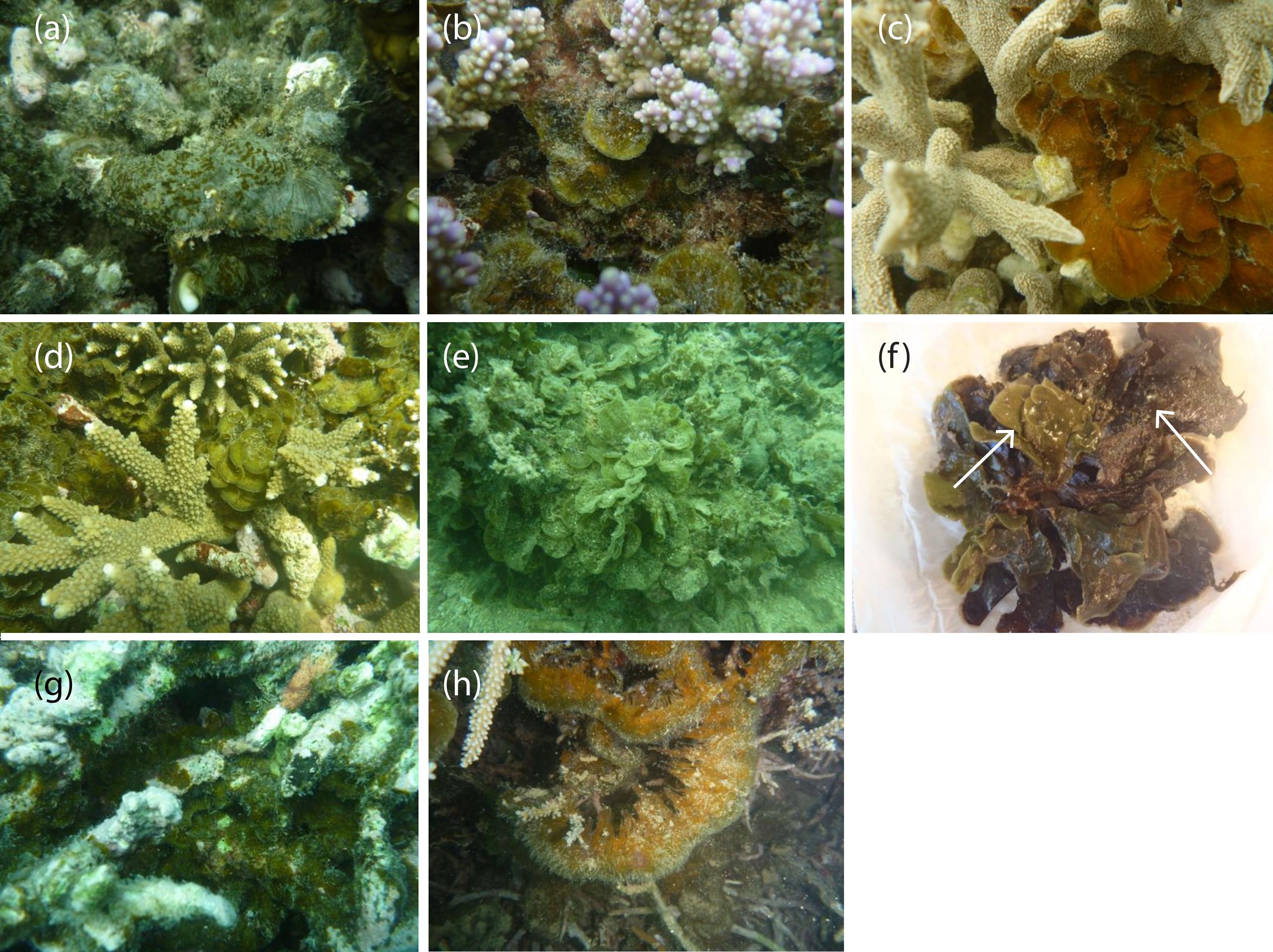




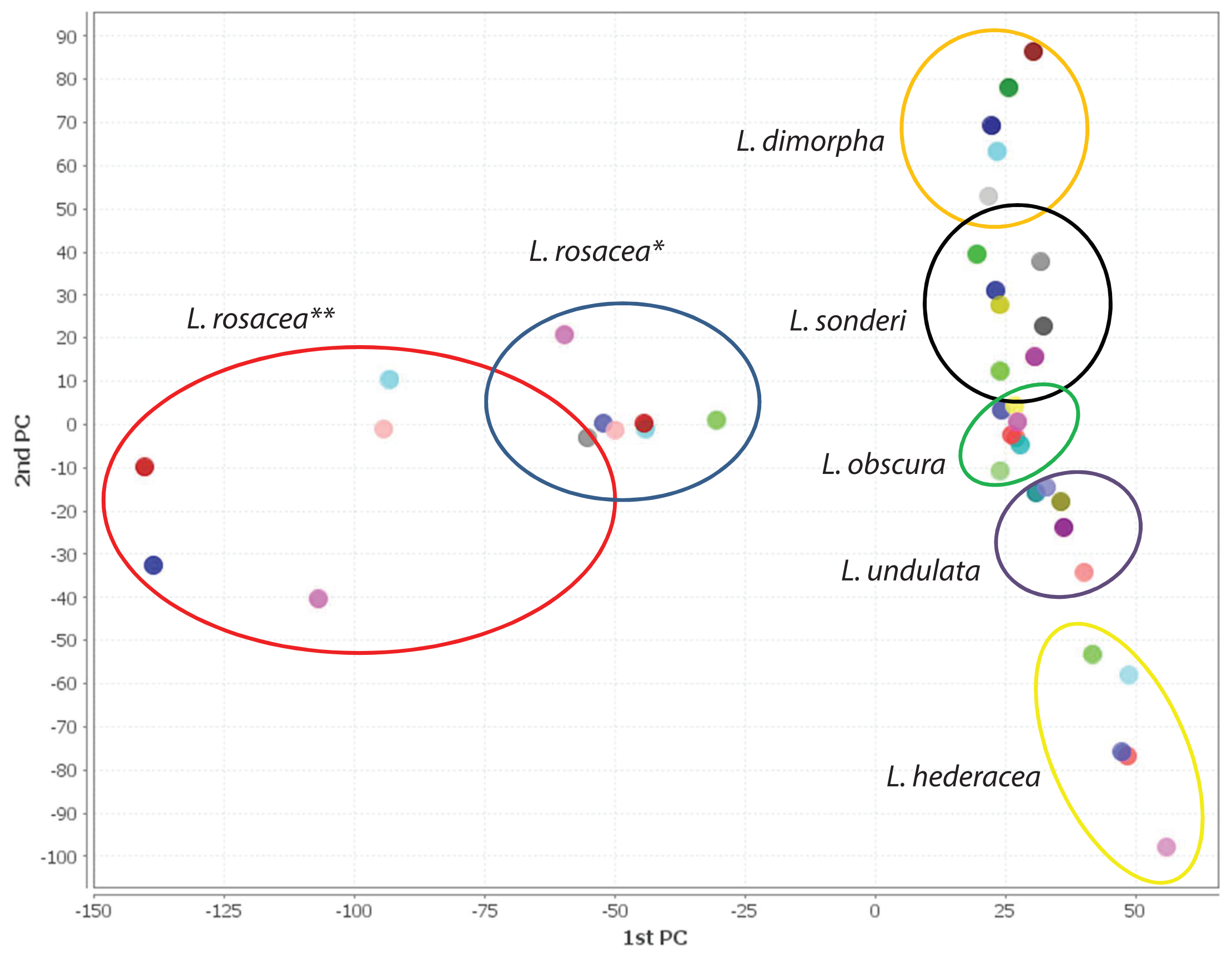




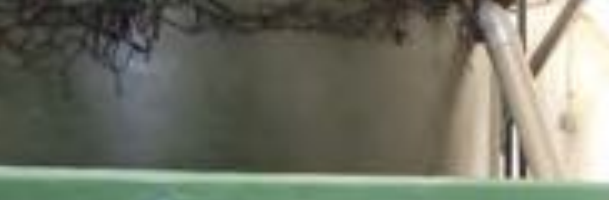




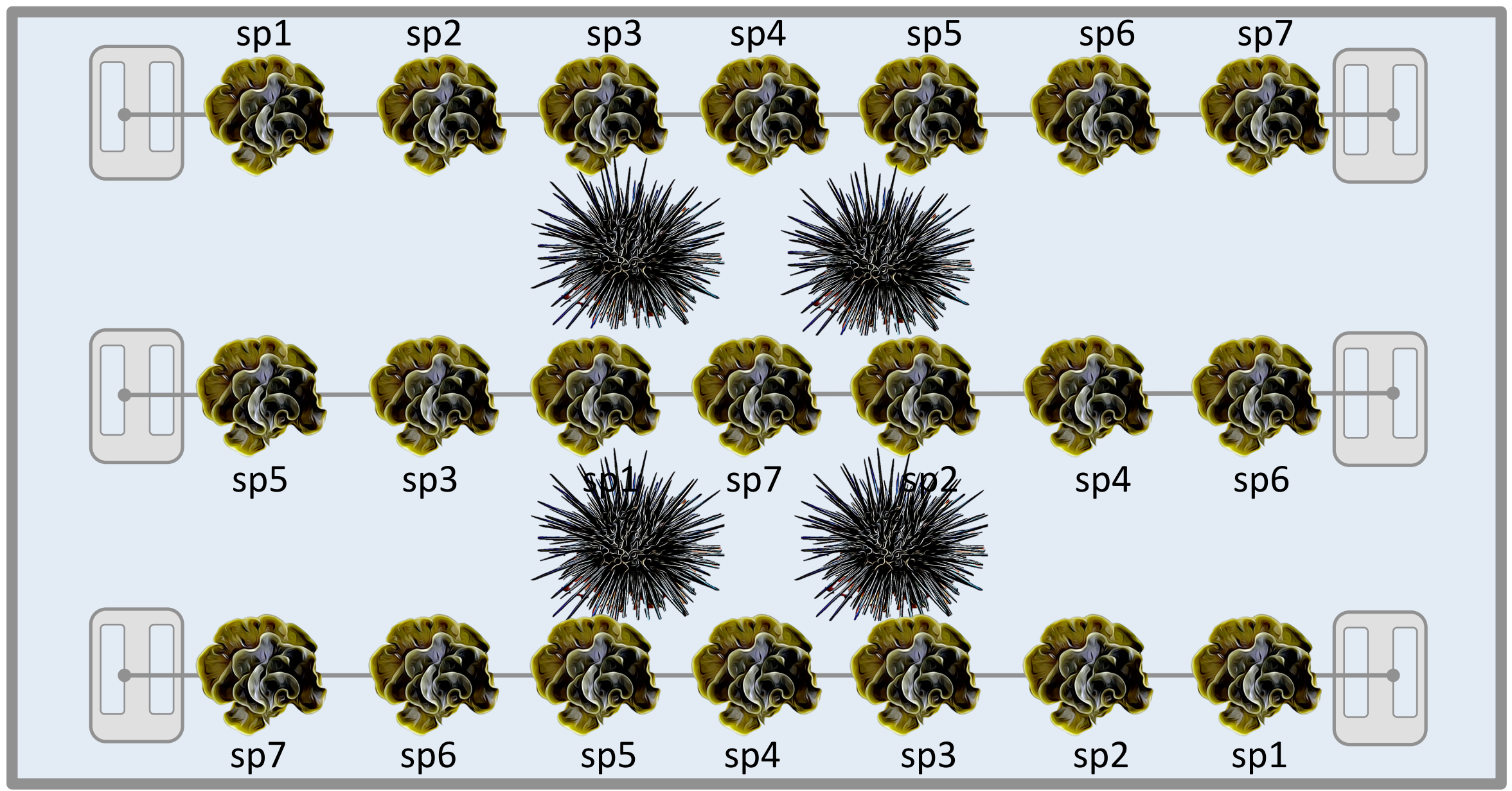

